\title{
Elastaz Aktivitesine Giresun Yöresindeki Bazı Yenilebilir Bitkilerin Farklı Çözücülerdeki Ekstrelerinin İnhibisyon Etkilerinin İncelenmesi
}

\author{
Bahar BİLGIN SÖKMEN ${ }^{*}$, Yasemin SAĞKAL ${ }^{1}$ \\ ${ }^{1}$ Giresun Üniversitesi, Fen Edebiyat Fakültesi, Kimya Bölümü, 28100, Giresun, TÜRKIYE
}

Geliș Tarihi: 09.05.2017

*Sorumlu Yazar: bahar.sokmen@giresun.edu.tr

Kabul Tarihi: 12.09.2017

\begin{abstract}
Özet
Elastazlar (E.C. 3.4.21.36), bağ dokunun önemli bir proteni olan elastini ayırma özelliğine sahip bir grup serin proteazlardır. Bu çalışmada, Giresun yöresinde yetişen 15 çeşit yenilebilir bitkinin farklı çözücülerdeki ekstrelerinin, elastaz enzim aktivitesi üzerindeki inhibitör etkisi incelendi. Bu amaçla, su, metil alkol ve etil asetat ile hazırlanan ekstrelerinin elastaz aktivitesi üzerine inhibitör etkileri spektrofotometrik olarak analiz edildi. Bu bitkiler arasında, kara lahananın (Brassica oleracea) sulu ekstresinin ( $\mathrm{IC}_{50}=0,0002 \pm 0,0001 \mu \mathrm{g} / \mathrm{mL}$ ), söğüt otunun (Polygonum lapathifolium) metil alkollü ekstresinin $\left(\mathrm{IC}_{50}=0,0003 \pm 0,0002 \mu \mathrm{g} / \mathrm{mL}\right)$ ve mendeğin (Aegopodium podagraria) etil asetatl ekstresinin $\left(\mathrm{IC}_{50}=0,0007 \pm 0,0001 \mu \mathrm{g} / \mathrm{mL}\right)$ elastaz enzimine karşı en yüksek inhibitör etkisine sahip olduğu bulundu. Analizlerin sonucunda, bitki ekstrelerinin elastaz üzerinde farklı inhibitör etkilerine sahip oldukları belirlendi. Çalışmada elde edilen sonuçlar, çalışılan bitkilerin alternatif bir anti-elastaz kaynağı olarak kullanılabileceğini açıkça göstermektedir.
\end{abstract}

Anahtar Sözcükler: Elastaz, Enzim, Enzim İnhibisyonu, İnhibitör, Bitki.

\section{Investigation of the Inhibition Effetcs of Extracts in Different Solvents of Some Edible Plants in the Region of Giresun on Elastase Activity}

\begin{abstract}
Elastases (Porcine pancreatic elastase, E.C. 3.4.21.36) are a group of serine proteases which possess the ability to cleave the important connective tissue protein elastin. In this study, inhibitory effects on elastase activity of the extracts in different solvents of 15 kinds of edible plants growing in Giresun province were investigated. For this purpose, inhibitory effects on elastase activity of the plants extracts which prepared with water, methyl alcohol and ethyl acetate were analysed spectrophotometrically. Among the plants, water extract of Brassica oleracea $\left(\mathrm{IC}_{50}=0.0002 \pm 0.0001\right.$ $\mu \mathrm{g} / \mathrm{mL})$; methyl alcohol extract of Polygonum lapathifolium $\left(\mathrm{IC}_{50}=0.0003 \pm 0.0002 \mu \mathrm{g} / \mathrm{mL}\right)$ and ethyl acetate extract of Aegopodium podagraria $\left(\mathrm{IC}_{50}=0.0007 \pm 0.0001 \mu \mathrm{g} / \mathrm{mL}\right)$ were found that they are the highest inhibitory effect against elastase enzyme. As a result of analysis, it was determined that the plant extracts showed different inhibitory effects on elastase. The data acquired in this study clearly shows that studied plants might be utilised as an alternative anti-elastase source.
\end{abstract}

Key Words: Elastase, Enzyme, Enzyme Inhibition, Inhibitory, Plant. 


\section{Giriş}

Elastazlar (E.C. 3.4.21.36), bağ dokunun önemli bir proteini olan elastini ayırma özelliğine sahip bir grup serin proteaz enzimleridir (Antonicelli ve ark., 2007). Yanısıra, elastazların romatoid artrit (kireçlenme), akciğer amfizemi ve kronik enflamatuar gibi hastalıklara sebep olduğu bilinmektedir (Robert, 2001). Elastin, bağ dokuya esneklik sağlayan bir ekstrasellüler matriks proteini olup; bu elastik lif formları cildin dermis ve cilt elastikiyetini etkilemektedir (Nar ve ark., 2001; Daamen, 2007). Pankreatik elastaz, özellikle akut pankreatit ya da pankreas kanseri gibi pankreas hastalıklarının durumlarını yansıtırken (Partelli ve ark., 2012); nötrofil elastaz (NE), çeşitli enflamatuar hastalık durumlarında artmaktadır (Vandivier ve ark., 2002). Bu nedenle elastaz enziminin inhibisyonu, klinik ve kozmetik endüstrileri açısından gün geçtikçe daha da önem kazanmaktadır.

Geleneksel halk ilaçları, yıllarca nesilden nesile aktarılarak varlığını devam ettiren ve halk arasında çeşitli hastalıkların tedavisinde yararlanılan doğal kaynaklı ilaçlardır. Bitkilerin yapısında bulunan kimyasal maddeler, sentez edilen kimyasal maddelere göre daha az yan etkilere sahip oldukları ve maliyetlerinin düşük olması gibi nedenlerle, bitkilere ve bitki ekstrelerine olan ilgi giderek artmaktadır. Bu nedenlerden ötürü, bitkilerden ve bitkisel kaynaklı olan birçok üründen izole edilen kimyasal maddeler, çeşitli hastalıkların tedavisinde kullanılmaktadır. Buna paralel olarak bu kullanımların bilimsel dayanağının olup olmadığının araştırılması da önem kazanmaktadır (Dinç, 2009). Bu çalışmada, Giresun İli’nin bazı yöresel bitkilerinin anti-elastaz inhibisyon aktiviteleri incelendi.

\section{Materyal ve Metot}

\subsection{Bitki Ekstrelerinin Hazırlanması}

Çalışmamızda kullanılan kara lahana, kara lahana çiçeği, sakarca, diken ucu, kaldirik, kuzu kulağı, çalı çileği, hoşuran, 1sırgan, ezeltere, pazı, mendek, gücükdene, söğüt otu ve yayla pancarı bitkileri, Giresun yöresindeki bazı köylerden ve semt pazarlarından mevsiminde temin edilip bol suyla yıkand1, destile sudan geçirildi ve serin bir yerde kurutuldu. Kurutulan bitkilerin sulu, metil alkollü ve etil asetatlı olmak üzere farklı polariteye sahip çözücülerdeki ekstreleri hazırlandı. 


\subsection{Sulu Ekstrelerin Hazırlanması}

Bitkiler kurutulup toz haline getirildikten sonra her bir bitkiden 10'ar g tart1lı cam balona konularak üzerine $100 \mathrm{~mL}$ destile su ilave edildi. Karışım geri soğutucu altında 8 saat reflüks edildi. Elde edilen karışım soğutulduktan sonra mavi bantlı süzgeç kağıdından süzüldü ve rota evaporatörde düşük basınç altında su tamamen karışımdan uzaklaştırıldı. Elde edilen herbir bitki ekstresi anti-elastaz aktivitesi tayini yapılıncaya kadar $+4{ }^{\circ} \mathrm{C}$ 'de muhafaza edildi.

\subsection{Metil Alkol ve Etil Asetat Ekstrelerinin Hazırlanması}

10 g kuru bitki tartıldı. Sokslet kartuşuna konularak sokslet aparatına yerleştirildi. Sokslet balonuna $100 \mathrm{~mL}$ \% 99'luk metil alkol ilave edilip 8 saat reflüks edildi. Elde edilen karışım soğutuldu ve rota evaporatöre yerleştirilerek düşük basınç altında metil alkol karışımdan uzaklaştırıldı. Aynı işlem etil asetat için de gerçekleştirildi. Elde edilen tüm bitki ekstreleri antielastaz aktivitesi tayini yapılıncaya kadar $+4{ }^{\circ} \mathrm{C}$ 'de muhafaza edildi.

\subsection{Anti-Elastaz Enzim Aktivite Tayini}

Elastaz inhibitör aktivitesi Moon ve arkadaşlarının (2010) yöntemine göre spektrofotometrik olarak tayin edildi (Moon ve ark., 2010). DMSO ile farklı konsantrasyonlarda hazırlanan herbir bitki ekstresinden $50 \mu \mathrm{L}$ alındı. Üzerine $0,2 \mathrm{M}$ pH's1 7,8 olan Tris-HCl tampon çözeltisinden 900 $\mu \mathrm{L}$ ilave edildi. Kontrol çözeltisine $100 \mu \mathrm{L}$ enzim; kör için ise enzim yerine aynı miktarda destile su eklendi. Kör, kontrol ve numune çözeltileri 15 dakika $37^{\circ} \mathrm{C}$ 'de inkübe edildi. İlk inkübasyondan sonra bütün tüplere $5 \mathrm{mM} 50 \mu \mathrm{L} \mathrm{N}$-süksinil-ala-ala-ala-p-nitroanilit (STANA) ilave edildi ve 37 ${ }^{\circ} \mathrm{C}$ 'de 30 dakika tekrar inkübasyon yapıldı. Kontrol ve numune çözeltilerinin spektrofotometrede 410 nm'de köre karşı absorbans değerleri okundu. Deneyler 3 kez tekrarlandı ve ortalaması alındı. Hazırlanan bitki ekstrelerinin ve standart maddenin anti-elastaz inhibisyon aktivitesi aşağıdaki denkleme göre hesapland1.

$$
\% \text { İnhibisyon }=\left[\left(A_{\text {kontrol }}-A_{\text {örnek }}\right) / A_{\text {kontrol }}\right] * 100
$$

Akontrol: Kontrol çözeltisinin 410 nm'de köre karşı absorbans değeri.

Ä̈rnek: Örnek çözeltisinin 410 nm'de köre karşı absorbans değeri.

Elastaz enziminin $\mathrm{IC}_{50}$ değeri, absise konsantrasyon, ordinata \% elastaz inhibisyon verilerinin uygulanması ile çizilen eğrinin lineer kesiminden elde edilen regresyon denkleminden hesaplandı. 


\section{Bulgular ve Tartışma}

$\mathrm{Bu}$ çalışmada Giresun yöresinde yetişen yenilebilir bitkilerin farklı çözücülerdeki ekstrelerinin anti-elastaz enzim aktiviteleri incelendi. Bitkilerin sulu, etil asetatlı ve metil alkollü ekstrelerinin farklı konsantrasyonları için hesaplanan inhibisyon değerleri ve konsantrasyon - \% elastaz inhibisyon grafikleri yardımı ile belirlenen IC50 değerleri Tablo 1- Tablo 3'te verilmiştir. Tablo 1 incelendiğinde; bitkilerin sulu ekstrelerinin, elastaz üzerindeki inhibisyon aktivitelerinin büyükten küçüğe sırasıyla kara lahana, ezeltere, kuzu kulağı, ısırgan, diken ucu, sakarca, çalı çileği, kaldirik, hoşuran, mendek, gücükdene, pazı, kara lahana çiçeği, yayla pancarı ve söğüt otu olarak sıralandığ1 görülmektedir. Sulu ekstrelerin arasında IC50 değerinin en düşük olması nedeniyle elastazı en yüksek oranda inhibe eden ekstrenin kara lahana ekstresi ( $\mathrm{IC}_{50}=0,0002 \pm 0,0001 \mu \mathrm{g} / \mathrm{mL}$ ) olduğu görülmektedir. Bitkilerin metil alkollü ekstrelerinin elastaz üzerindeki inhibisyon aktivitelerinin büyükten küçüğe sırasıyla söğüt otu, gücükdene, çalı çileği, kara lahana, mendek, sakarca, kuzu kulağı, pazı, ısırgan, hoşuran, diken ucu, yayla pancarı, kara lahana çiçeği, kaldirik ve ezeltere olarak sıralandığı görülmektedir (Tablo 2). Metil alkollü ekstrelerin arasında elastazı en yüksek oranda inhibe eden ekstrenin sögüt otu ekstresi $\left(\mathrm{IC}_{50}=0,0003 \pm 0,0002 \mu \mathrm{g} / \mathrm{mL}\right)$ olduğu görülmektedir. Bitkilerin etil asetatlı ekstrelerinin elastaz üzerindeki inhibisyon aktivitelerinin büyükten küçüğe sırasıyla mendek, kaldirik, sakarca, kuzu kulağı, yayla pancarı, hoşuran, ezeltere, pazı, söğüt otu, kara lahana, karalahana çiçeği, gücükdene, diken ucu, 1sırgan ve çalı çileği olarak sıralandığı görülmektedir. Etil asetatlı ekstrelerin arasında elastazı en yüksek oranda inhibe eden ekstrenin mendek ekstresi ( $\mathrm{IC}_{50}=0,0007 \pm 0,0001 \mu \mathrm{g} / \mathrm{mL}$ ) olduğu görülmektedir (Tablo 3).

İnsanlar çok eski dönemlerden beri bitkileri gıda olarak, boya elde etmek, süs bitkisi ve tedavi amacıyla kullanmışlardır. Bu bitkilerin halk hekimliğindeki kullanımı antik çağdan itibaren devamlı bir artış göstermektedir (Koca ve ark., 2011). Özellikle son yıllarda, çoğu insan sentetik ilaçların yan etkilerinden dolayı bitkisel tedaviye yönelmiştir. Günümüzde Dünya Sağlı Örgütünün (WHO) incelemelerine göre, tedavi amacıyla kullanılan tıbbi bitkilerin sayısı yaklaşık olarak 20.000'dir (Kalaycıŏlu ve Öner, 1994).

Yenilebilir bitkiler, çeşitli biyolojik aktivite gösteren flavonoidler, vitaminler, terpenoidler alkoloidler, orgonosülfürler, pigmentler ve diğer fenolik bileşikler gibi fitokimyasallar açısından zengindirler (Matsubara ve ark., 2003) ve yüksek antioksidan aktiviteye sahip bileşikler içermektedirler (Ho ve ark., 1994). Antikarsinojenik, antiaging, antimutajenik gibi pekçok biyolojik fonksiyon, bu antioksidan bileşiklerden kaynaklanmaktadır (Nishina ve ark., 1991). Terpenoidler, flavonoidler ve fenolik bileşenlerin anti-elastaz aktiviteye sahip olduğu bulunmuştur (Lee ve ark., 2001). Böylece, yenilebilir bitkilerin elastaz kontrolü için bir kaynak olabileceği düşünülmektedir. Bu çalışmada, Giresun yöresinde yetişen bitkilerin elastaz inhibitörü olup olmadığı araştırıldı. 
Tablo 1. Bitkilerin Sulu Ekstrelerinin Elastaz Enzimi Üzerindeki \% Elastaz İnhibisyonu ve $\mathrm{IC}_{50}$ Değerleri

\begin{tabular}{|c|c|c|c|}
\hline Bitki Adı & $\begin{array}{c}\text { Konsantrasyon } \\
(\mu \mathrm{g} / \mathrm{mL})\end{array}$ & \% İnhibisyon* & IC $_{50}$ Değeri $(\mu \mathrm{g} / \mathrm{mL})^{*}$ \\
\hline & $1 \times 10^{-6}$ & $17,03 \pm 4,20$ & \\
\hline & $1 \times 10^{-5}$ & $18,55 \pm 2,67$ & \\
\hline \multirow[t]{3}{*}{ Çalı Çileği } & $1 \times 10^{-4}$ & $21,46 \pm 1,63$ & $0,0078 \pm 0,002$ \\
\hline & $1 \times 10^{-3}$ & $23,11 \pm 1,75$ & \\
\hline & $1 \times 10^{-6}$ & $38,80 \pm 13,61$ & \\
\hline \multirow{4}{*}{ Kuzu Kulağı } & $1 \times 10^{-5}$ & $39,67 \pm 13,66$ & \\
\hline & $1 \times 10^{-4}$ & $40,76 \pm 14,04$ & $0,0030 \pm 0,003$ \\
\hline & $1 \times 10^{-3}$ & $42,23 \pm 12,59$ & \\
\hline & $1 \times 10^{-1}$ & $36,14 \pm 4,52$ & \\
\hline \multirow[t]{4}{*}{ Yayla Pancarı } & 1 & $38,06 \pm 5,57$ & $12,8420 \pm 2,210$ \\
\hline & 10 & $39,52 \pm 6$ & \\
\hline & $1 \times 10^{-6}$ & $37,44 \pm 14,54$ & \\
\hline & $1 \times 10^{-5}$ & $38,32 \pm 14,91$ & $0,0043 \pm 0,006$ \\
\hline \multirow{3}{*}{ Diken Ucu } & $1 \times 10^{-4}$ & $39,58 \pm 15,82$ & \\
\hline & $1 \times 10^{-3}$ & $41,64 \pm 16,11$ & \\
\hline & $1 \times 10^{-6}$ & $41,91 \pm 1,16$ & \\
\hline \multirow[t]{3}{*}{ Kara Lahana } & $1 \times 10^{-5}$ & $45,32 \pm 4,04$ & $0,0002 \pm 0,0001$ \\
\hline & $1 \times 10^{-4}$ & $46,69 \pm 4,03$ & \\
\hline & $1 \times 10^{-4}$ & $39,42 \pm 11,51$ & \\
\hline \multirow[t]{5}{*}{ Mendek } & $1 \times 10^{-3}$ & $42,30 \pm 10,89$ & $0,1158 \pm 0,031$ \\
\hline & $1 \times 10^{-2}$ & $43,76 \pm 11,60$ & \\
\hline & $1 \times 10^{-1}$ & $44,81 \pm 12,190$ & \\
\hline & $1 \times 10^{-6}$ & $30,10 \pm 4,10$ & \\
\hline & $1 \times 10^{-5}$ & $31,65 \pm 3,33$ & $0,0044 \pm 0,0008$ \\
\hline \multirow[t]{4}{*}{ Sakarca } & $1 \times 10^{-4}$ & $33,19 \pm 2,56$ & \\
\hline & $1 \times 10^{-3}$ & $35,53 \pm 3,50$ & \\
\hline & $1 \times 10^{-5}$ & $36,49 \pm 0,38$ & \\
\hline & $1 \times 10^{-4}$ & $37,57 \pm 0,38$ & $0,0500 \pm 0,0161$ \\
\hline \multirow[t]{4}{*}{ Kaldirik } & $1 \times 10^{-3}$ & $38,65 \pm 0,38$ & \\
\hline & $1 \times 10^{-2}$ & $40,00 \pm 0,76$ & \\
\hline & $1 \times 10^{-2}$ & $24,73 \pm 2,57$ & \\
\hline & $1 \times 10^{-1}$ & $25,46 \pm 2,57$ & $14,6300 \pm 0,218$ \\
\hline \multirow[t]{3}{*}{ Söğüt Otu } & 1 & $31,09 \pm 0,2514$ & \\
\hline & 10 & $34,18 \pm 0,51$ & \\
\hline & $1 \times 10^{-6}$ & $36,09 \pm 1,85$ & \\
\hline \multirow[t]{5}{*}{ Isırgan } & $1 \times 10^{-5}$ & $38,26 \pm 1,23$ & $0,0034 \pm 0,002$ \\
\hline & $1 \times 10^{-4}$ & $39,57 \pm 0,62$ & \\
\hline & $1 \times 10^{-3}$ & $42,18 \pm 1,85$ & \\
\hline & $1 \times 10^{-5}$ & $39,70 \pm 0,23$ & \\
\hline & $1 \times 10^{-4}$ & $40,26 \pm 0,47$ & $0,1033 \pm 0,012$ \\
\hline \multirow{3}{*}{ Hoşuran } & $1 \times 10^{-3}$ & $40,49 \pm 0,47$ & \\
\hline & $1 \times 10^{-2}$ & $41,09 \pm 0,23$ & \\
\hline & $1 \times 10^{-3}$ & $17,10 \pm 2,28$ & \\
\hline \multirow[t]{4}{*}{ Pazı } & $1 \times 10^{-2}$ & $19,68 \pm 0,46$ & $2,2466 \pm 0,046$ \\
\hline & $1 \times 10^{-1}$ & $20,97 \pm 0,46$ & \\
\hline & 1 & $22,26 \pm 0,45$ & \\
\hline & $1 \times 10^{-6}$ & $38,23 \pm 15,11$ & \\
\hline \multirow[t]{4}{*}{ Ezeltere } & $1 \times 10-^{5}$ & $38,89 \pm 15,20$ & $0,0013 \pm 0,004$ \\
\hline & $1 \times 10^{-4}$ & $39,55 \pm 15,29$ & \\
\hline & $1 \times 10^{-3}$ & $40,70 \pm 15,21$ & \\
\hline & $1 \times 10^{-4}$ & $37,07 \pm 16,72$ & \\
\hline \multirow{3}{*}{ Gücükdene } & $1 \times 10^{-3}$ & $37,75 \pm 17,02$ & $0,4863 \pm 0,684$ \\
\hline & $1 \times 10^{-2}$ & $38,87 \pm 17,93$ & \\
\hline & $1 \times 10^{-1}$ & $40,04 \pm 16,89$ & \\
\hline
\end{tabular}

*Değerler üç deneyin ortalamasıdır \pm standart sapma. 
Tablo 2. Bitkilerin Metil alkol Ekstrelerinin Elastaz Enzimi Üzerindeki \% Elastaz İnhibisyonu ve $\mathrm{IC}_{50}$ Değerleri

\begin{tabular}{|c|c|c|c|}
\hline Bitki Adı & $\begin{array}{c}\text { Konsantrasyon } \\
(\mu \mathrm{g} / \mathrm{mL})\end{array}$ & \% İnhibisyon* & $\begin{array}{c}\text { IC } \text { ICo Değeri } \text { Deg } \\
(\mu \mathrm{gL}) *\end{array}$ \\
\hline & $1 \times 10^{-6}$ & $21,81 \pm 10,96$ & \\
\hline \multirow[t]{2}{*}{ Çalı Çileği } & $1 \times 10^{-5}$ & $22,64 \pm 11,02$ & $0,0015 \pm 0,00019$ \\
\hline & $1 \times 10^{-4}$ & $23,86 \pm 10,53$ & \\
\hline \multirow[t]{4}{*}{ Kuzu Kulağı } & $1 \times 10^{-6}$ & $34,10 \pm 16,41$ & \\
\hline & $1 \times 10^{-5}$ & $35,20 \pm 16,78$ & $0,0065 \pm 0,006$ \\
\hline & $1 \times 10^{-4}$ & $36,26 \pm 15,92$ & \\
\hline & $1 \times 10^{-3}$ & $36,90 \pm 15,65$ & \\
\hline \multirow[t]{5}{*}{ Yayla Pancarı } & $1 \times 10^{-4}$ & $33,93 \pm 3,88$ & \\
\hline & $1 \times 10^{-3}$ & $37,43 \pm 5,52$ & $0,5165 \pm 0,488$ \\
\hline & $1 \times 10^{-2}$ & $39,06 \pm 6,99$ & \\
\hline & $1 \times 10^{-1}$ & $40,19 \pm 7,75$ & \\
\hline & $1 \times 10^{-4}$ & $35,48 \pm 18,92$ & \\
\hline \multirow[t]{3}{*}{ Diken Ucu } & $1 \times 10^{-3}$ & $36,39 \pm 18,71$ & $0,3972 \pm 0,531$ \\
\hline & $1 \times 10^{-2}$ & $38,54 \pm 17,29$ & \\
\hline & $1 \times 10^{-1}$ & $38,99 \pm 17,18$ & \\
\hline \multirow[t]{4}{*}{ Kara Lahana } & $1 \times 10^{-6}$ & $30,68 \pm 25,39$ & \\
\hline & $1 \times 10^{-5}$ & $31,25 \pm 25,55$ & $0,0015 \pm 0,002$ \\
\hline & $1 \times 10^{-4}$ & $32,39 \pm 25,87$ & \\
\hline & $1 \times 10^{-6}$ & $37,16 \pm 4,30$ & \\
\hline \multirow[t]{4}{*}{ Mendek } & $1 \times 10^{-5}$ & $38,85 \pm 4,67$ & $0,0045 \pm 0,0002$ \\
\hline & $1 \times 10^{-4}$ & $40,06 \pm 4,36$ & \\
\hline & $1 \times 10^{-3}$ & $41,01 \pm 3,71$ & \\
\hline & $1 \times 10^{-6}$ & $27,10 \pm 0,14$ & \\
\hline \multirow[t]{4}{*}{ Sakarca } & $1 \times 10^{-5}$ & $28,44 \pm 0,62$ & $0,0061 \pm 0,001$ \\
\hline & $1 \times 10^{-4}$ & $29,65 \pm 0,50$ & \\
\hline & $1 \times 10^{-3}$ & $31,69 \pm 0,44$ & \\
\hline & $1 \times 10^{-3}$ & $41,39 \pm 0,40$ & \\
\hline \multirow[t]{4}{*}{ Kara Lahana Çiçeği } & $1 \times 10^{-2}$ & $43,33 \pm 1,57$ & $0,9189 \pm 0,113$ \\
\hline & $1 \times 10^{-1}$ & $46,39 \pm 5,11$ & \\
\hline & 1 & $50,28 \pm 0,39$ & \\
\hline & $1 \times 10^{-3}$ & $13,13 \pm 0,88$ & \\
\hline \multirow[t]{3}{*}{ Kaldirik } & $1 \times 10^{-2}$ & $14,69 \pm 0,45$ & $1,8671 \pm 9,962$ \\
\hline & $1 \times 10^{-1}$ & $15,94 \pm 0,45$ & \\
\hline & $1 \times 10^{-6}$ & $29,44 \pm 0,57$ & \\
\hline \multirow[t]{3}{*}{ Söğüt Otu } & $1 \times 10^{-5}$ & $31,86 \pm 0,57$ & $0,0003 \pm 0,0002$ \\
\hline & $1 \times 10^{-4}$ & $35,89 \pm 2,85$ & \\
\hline & $1 \times 10^{-2}$ & $48,30 \pm 0,80$ & \\
\hline \multirow[t]{3}{*}{ Isırgan } & $1 \times 10^{-1}$ & $0,285 \pm 0,40$ & $0,0994 \pm 0,0008$ \\
\hline & 1 & $51,42 \pm 0,40$ & \\
\hline & $1 \times 10^{-2}$ & $47,69 \pm 0,70$ & \\
\hline \multirow[t]{4}{*}{ Hoşuran } & $1 \times 10^{-1}$ & $49,67 \pm 1,17$ & $0,1007 \pm 0,002$ \\
\hline & 1 & $50,33 \pm 0,70$ & \\
\hline & 10 & $51,32 \pm 0,70$ & \\
\hline & $1 \times 10^{-6}$ & $20,00 \pm 2,22$ & \\
\hline \multirow[t]{4}{*}{ Pazı } & $1 \times 10-^{5}$ & $25,10 \pm 0,56$ & $0,0594 \pm 0,015$ \\
\hline & $1 \times 10^{-4}$ & $27,45 \pm 0,55$ & \\
\hline & $1 \times 10^{-3}$ & $28,04 \pm 0,28$ & \\
\hline & $1 \times 10^{-3}$ & $32,95 \pm 19,50$ & \\
\hline \multirow[t]{4}{*}{ Ezeltere } & $1 \times 10^{-2}$ & $35,53 \pm 16,37$ & $3,2758 \pm 0,918$ \\
\hline & $1 \times 10^{-1}$ & $38,59 \pm 13,07$ & \\
\hline & 1 & $39,07 \pm 12,91$ & \\
\hline & $1 \times 10^{-6}$ & $30,88 \pm 0,57$ & \\
\hline \multirow[t]{2}{*}{ Gücükdene } & $1 \times 10^{-5}$ & $34,29 \pm 1,35$ & $0,0005 \pm 0,0001$ \\
\hline & $1 \times 10^{-4}$ & $35,64 \pm 1,92$ & \\
\hline
\end{tabular}

*Değerler üç deneyin ortalamasıdır \pm standart sapma. 
Tablo 3. Bitkilerin Etil Asetat Ekstrelerinin Elastaz Enzimi Üzerindeki \% Elastaz İnhibisyonu ve $\mathrm{IC}_{50}$ Değerleri

\begin{tabular}{|c|c|c|c|}
\hline Bitki Adı & $\begin{array}{l}\text { Konsantrasyon } \\
(\mu \mathrm{g} / \mathrm{mL})\end{array}$ & \% İnhibisyon* & $\begin{array}{l}\text { IC50 Değeri } \\
(\mu \mathrm{g} / \mathrm{mL})^{*}\end{array}$ \\
\hline & $1 \times 10^{-3}$ & $19,12 \pm 4,94$ & \\
\hline \multirow[t]{3}{*}{ Çalı Çileği } & $1 \times 10^{-2}$ & $22,55 \pm 8,68$ & $6,6014 \pm 1,042$ \\
\hline & $1 \times 10^{-1}$ & $24,16 \pm 7,64$ & \\
\hline & 1 & $25,76 \pm 6,60$ & \\
\hline \multirow[t]{4}{*}{ Kuzu Kulağg } & $1 \times 10^{-6}$ & $33,76 \pm 19,45$ & \\
\hline & $1 \times 10^{-5}$ & $35,88 \pm 17,41$ & $0,0055 \pm 0,006$ \\
\hline & $1 \times 10^{-4}$ & $36,52 \pm 17,47$ & \\
\hline & $1 \times 10^{-3}$ & $37,39 \pm 17,52$ & \\
\hline \multirow[t]{5}{*}{ Yayla Pancarı } & $1 \times 10^{-6}$ & $30,78 \pm 3,61$ & \\
\hline & $1 \times 10^{-5}$ & $33,58 \pm 6,72$ & $0,0079 \pm 0,006$ \\
\hline & $1 \times 10^{-4}$ & $34,84 \pm 6,84$ & \\
\hline & $1 \times 10^{-3}$ & $35,30 \pm 6,65$ & \\
\hline & $1 \times 10^{-3}$ & $37,45 \pm 14,55$ & \\
\hline \multirow[t]{3}{*}{ Diken Ucu } & $1 \times 10^{-2}$ & $38,51 \pm 15,17$ & $3,2614 \pm 4,375$ \\
\hline & $1 \times 10^{-1}$ & $41,07 \pm 15,03$ & \\
\hline & 1 & $42,07 \pm 14,97$ & \\
\hline \multirow[t]{5}{*}{ Kara Lahana } & $1 \times 10^{-4}$ & $27,61 \pm 28,76$ & \\
\hline & $1 \times 10^{-3}$ & $28,98 \pm 28,76$ & $0,4313 \pm 0,551$ \\
\hline & $1 \times 10^{-2}$ & $29,55 \pm 28,93$ & \\
\hline & $1 \times 10^{-1}$ & $32,28 \pm 27,04$ & \\
\hline & $1 \times 10^{-6}$ & $47,24 \pm 0,45$ & \\
\hline \multirow[t]{4}{*}{ Mendek } & $1 \times 10^{-5}$ & $48,44 \pm 0,13$ & $0,0007 \pm 0,0001$ \\
\hline & $1 \times 10^{-4}$ & $49,39 \pm 0,52$ & \\
\hline & $1 \times 10^{-3}$ & $50,60 \pm 0,52$ & \\
\hline & $1 \times 10^{-5}$ & $38,00 \pm 4,24$ & \\
\hline \multirow[t]{3}{*}{ Sakarca } & $1 \times 10^{-4}$ & $39,34 \pm 4,72$ & $0,0042 \pm 0,001$ \\
\hline & $1 \times 10^{-3}$ & $41,18 \pm 4,49$ & \\
\hline & $1 \times 10^{-3}$ & $40,24 \pm 1,70$ & \\
\hline \multirow[t]{4}{*}{ Kara Lahana Çiçeği } & $1 \times 10^{-2}$ & $44,59 \pm 1,06$ & $1,2197 \pm 0,543$ \\
\hline & $1 \times 10^{-1}$ & $46,10 \pm 0,22$ & \\
\hline & 1 & $49,01 \pm 2,89$ & \\
\hline & $1 \times 10^{-6}$ & $15,62 \pm 1,77$ & \\
\hline \multirow[t]{4}{*}{ Kaldirik } & $1 \times 10^{-5}$ & $18,13 \pm 0,89$ & $0,0032 \pm 0,001$ \\
\hline & $1 \times 10^{-4}$ & $21,25 \pm 1,77$ & \\
\hline & $1 \times 10^{-3}$ & $28,75 \pm 3,54$ & \\
\hline & $1 \times 10^{-3}$ & $19,40 \pm 0,77$ & \\
\hline \multirow[t]{3}{*}{ Söğüt Otu } & $1 \times 10^{-2}$ & $22,37 \pm 3,35$ & $0,3381 \pm 0,050$ \\
\hline & $1 \times 10^{-1}$ & $29,09 \pm 2,57$ & \\
\hline & $1 \times 10^{-2}$ & $38,26 \pm 1,23$ & \\
\hline \multirow[t]{3}{*}{ Isırgan } & $1 \times 10^{-1}$ & $40,40 \pm 0,62$ & $3,4764 \pm 0,310$ \\
\hline & 1 & $42,18 \pm 0,62$ & \\
\hline & $1 \times 10^{-5}$ & $36,69 \pm 0,57$ & \\
\hline \multirow[t]{4}{*}{ Hoşuran } & $1 \times 10^{-4}$ & $38,31 \pm 0,57$ & $0,0401 \pm 0,013$ \\
\hline & $1 \times 10^{-3}$ & $39,92 \pm 0,57$ & \\
\hline & $1 \times 10^{-2}$ & $41,13 \pm 1,14$ & \\
\hline & $1 \times 10^{-5}$ & $22,58 \pm 0,91$ & \\
\hline \multirow[t]{4}{*}{ Pazı } & $1 \times 10^{-4}$ & $23,23 \pm 0,91$ & $0,1333 \pm 0,002$ \\
\hline & $1 \times 10^{-3}$ & $24,19 \pm 1,37$ & \\
\hline & $1 \times 10^{-2}$ & $25,17 \pm 0,91$ & \\
\hline & $1 \times 10^{-4}$ & $33,06 \pm 16,27$ & \\
\hline \multirow[t]{3}{*}{ Ezeltere } & $1 \times 10^{-3}$ & $36,01 \pm 18,75$ & $0,1081 \pm 0,140$ \\
\hline & $1 \times 10^{-2}$ & $36,68 \pm 18,84$ & \\
\hline & $1 \times 10^{-2}$ & $30,08 \pm 4,82$ & \\
\hline \multirow[t]{2}{*}{ Gücükdene } & $1 \times 10^{-1}$ & $41,55 \pm 20,37$ & $1,3020 \pm 0,719$ \\
\hline & 1 & $45,31 \pm 25,010$ & \\
\hline
\end{tabular}

*Değerler üç deneyin ortalamasıdır \pm standart sapma. 
Sonuç olarak, çalışmamızda kullandığımız 15 bitkinin sulu, metil alkolü ve etil asetatlı ekstrelerinin tümünde elastaz inhibitör etkisi saptanmıştır. Bunlardan sulu bitki ekstrelerinden kara lahana, ezeltere, kuzu kulağ1 ve 1sırgan; metil alkollü ekstrelerinden söğüt otu, gücükdene, çalı çileği, kara lahana ve mendek; etil asetatlı ekstrelerinden mendek, kaldirik, sakarca ve kuzu kulağının elastaz inhibitör etkisi diğer bitkilere göre daha yüksek oranda bulundu.

Elastaz inhibisyonu ile ilgili yapılan bir çalışmada, Epilobium angustifolium yapraklarının sulu ekstresinde elastaz inhibisyon aktivitesi incelenmiş ve bitkinin iyi bir elastaz inhibitörü $\left(\right.$ IC $_{50}=$ $42,72 \pm 2,38 \mu \mathrm{g} / \mathrm{mL}$ ) olduğu bildirilmiştir (Onar ve ar., 2012). Diğer bir çalışmada, Yemen yöresinde bulunan Pavetta longiflora, Ceropegia rupicola, Aspilia helianthoides, Kniphofia sumarae ve Plectranthus cf. barbatus bitkilerinin diklorometan, metil alkol ve sulu ekstrelerinde elastaz inhibisyon aktivitesi incelenmiş ve Aspilia helianthoides bitkisinin en yüksek anti-elastaz aktivitesine $\left(\mathrm{IC}_{50}=0,4 \mu \mathrm{g} / \mathrm{mL}\right.$ ) sahip olduğu bulunmuştur (Alasbahi ve ark., 2008). Kim ve arkadaşları tarafindan gerçekleştirilen diğer bir çalışmada Callistemon lanceolatus bitkisinin etil alkol ekstresinde elastaz inhibisyon aktivitesi incelenmiş ve bitkinin iyi bir elastaz inhibitörü (IC50 = 20,2 $\mu \mathrm{g} / \mathrm{mL}$ ) olduğu bulunmuştur (Kim ve ark., 2009). Masuda ve arkadaşları'nın yürüttüğü bir çalışmada ise, Morinda citrifolia bitkisinin meyve, yaprak ve tohumlarından ayrı ayrı hazırlanan etil alkollü ekstrelerinde elastaz inhibisyon aktivitesi incelenmiş ve bu bitkinin meyvesinin daha yüksek elastaz inhibisyon aktivitesi ( $\mathrm{IC}_{50}=12 \mu \mathrm{g} / \mathrm{mL}$ ) gösterdiği bulunmuştur (Masuda ve arkadaşları (2009).

\section{Sonuçlar ve Öneriler}

Yapılan literatür araştırmalarından farklı bitkilerin anti-elastaz aktiviteleri üzerine çalışmalar yapılmış olup, Giresun yöresinde yetişen bitkilerin elastaz inhibisyonu ile ilgili herhangi bir çalışmaya rastlanmamıştır. Çalışmamızda, yüksek elastaz inhibitör etkisi gösteren karalahana, söğüt otu ve mendeğin elastaz inhibitörü olarak kırışıklık gidermede, cilt beyazlatmada, kuru cilt ve deri kanseri gibi rahatsızlıklarda fitoterapotik ajan olarak kozmetik sektöründe bitkisel ilaç olarak kullanımının uygun olacağı ileri sürülebilir. Bu bitkilerin etken maddelerinin izole edilerek yapı tayinlerinin yapılması ve bu maddelerin enzim inhibisyonlarının in vivo deneylerle de kanıtlanması için daha ileri düzeyde çalışmalara gereksinim vardır. Çalışmamızdan elde edilen sonuçlara göre, çalışmada en yüksek inhibitör aktivitesine sahip bitki ekstrelerinin yaşlanma karşıtı kozmetiklere aday olabileceği düşünülmektedir. 


\section{Teşekkür}

$\mathrm{Bu}$ çalışma, Giresun Üniversitesi Bilimsel Araştırma Projeleri Koordinasyon Birimi tarafından FEN-BAP-C-160512-09 nolu proje ile desteklenmiştir.

\section{Kaynaklar}

Alasbahi, R. and Melzig, M. (2008). The in vitro Inhibition of Human Neutrophil Elastase Activity by some Yemeni Medicinal Plants. 2008. Scienta Pharmaceutica, 76, 471-483.

Antonicelli, F., Bellon, G., Debelle, L. and Horneback, W. (2007). Elastin-elastases and inflamm-aging. Current Topics in Developmental Biology, 79, 99-155.

Daamen, W. F., Verkamp, J. H., Van Hest, J. C. M. and Kuppevelt, T. H. (2007). Elastinas a biomaterial for tissue engineering. Biomaterials, 28, 4378-4398.

Dinç, Y. (2009). Üreaz Enziminin Bazı Tıbbi Bitkiler Tarafindan İnhibisyonu. Yüksek Lisans Tezi, İstanbul Üniversitesi, Fen Bilimleri Enstitüsü, İstanbul.

Ho, C. T., Ferraro, T., Chen, Q., Rosen, R. T. and Huang M. T. (1994). Phytochemicals in Teas and Rosemary and Their Cancer-Preventive Properties. Food Phytochemicals for Cancer Prevention. II. Tea, Spices and Herbs. (Eds) Ho, C.-T., Osawa, T., Huang, M. T., Rosen, R. T. ACS Symposium Series 547. Washington DC, American Chemical Society, 2-19.

Kalaycıŏlu, A., Öner, C. (1994). Bazı Bitki Ekstraktlarının Antimutajenik Etkilerinin Amest-salmonella Test Sistemi İle Araştırılması. The Turkish Journal of Botany, 18, 117-122.

Kim, J. H., Byun, J. C., Bandi, A. K. R., Hyun, C. G. and Lee, N. H. (2009). Compounds with Elastase Inhibition and Free Radical Scavenging Activities from Callistemon lanceolatus. Journal of Medicinal Plants Research, 3, 914-920.

Koca, İ., Hasbay, İ. ve Bostancı, Ş. (2011, Ekim). Samsun ve Çevresinde Sebze Olarak Kullanılan Bazı Yabani Bitkiler ve Tüketim Şekilleri. Samsun Sempozyumu, Samsun.

Lee, K. K., Choy, J. J., Park, E. J. and Choiy, J. D. (2001). Anti-Elastase and Anti-Hyaluronidase of Phenolic Substance from Areca Catechu as A New Anti-Ageing Agent. International Journal of Cosmetic Science, 23, 341-346.

Masuda, M., Murata, K., Fukuhama, A., Naruto, S., Fujita,T., Uwaya, A., Isami, F. and Matsuda, H. (2009). Inhibitory Effects of Constituents of Morinda citrifolia Seeds on Elastase and Tyrosinase. Journal of Natural Medicines, 63, 267-273.

Matsubara, S., Shibata, H., Ishikawa, F., Yokokura, T., Takahashi, M., Sugimura, T., Wakabayashi, K. (2003). Suppression of Helicobacter pylori induced gastiritis by green tea extract in mongolian gerbils. Biochemical and Biophysical Research Communications, 310, 715-719.

Moon, J.Y., Yim, E.Y., Song, G., Lee, N.H. and Hyun, C.G. 2010. Screening of elastase and tyrosinase inhibitory activity from Jeju Island plants. Eur Asian Journal of Bio Sciences, 4, 41-53.

Nar, H., Werle, K., Bauer, M. M. T., Dollinger, H. and Jung, B. (2001). Crystal structure of human macrophage elastase (MMP-12) in complex with a hydroxamic acid inhibitor. Journal of Molecular Biology 312, $743-751$.

Nishina, A., Kubota, K., Kameoka, H. and Osawa, T. (1991). Antioxidizing Component, Musizin, in Rumex Japonicus Houtt. Journal of the American Oil Chemists Society, 68, 735-739.

Onar, H.C., Yusufoğlu, A., Türker, G. ve Yanardağ, R. (2012). Elastase, tyrosinase and lipoxygenase inhibition and antioxidant activity of an aqueous extract from Epilobium angustifolium L. leaves. Journal of Medicinal Plants Research, 6, 716-726.

Partelli, S., Frulloni, L., Minniti, C., Bassi, C., Barugola, G., Onofrio, M., Stefano, C. and Falconi, M. (2012). Faecal elastase-1 is an independent predictor of survival in advanced pancreatic cancer. Digestive and Liver Disease, 44, 945-951.

Robert, L. (2001). Extracellular matrix and aging: a review of mechanisms and interventions. Cosmet Toiletries Magazine, 116, 61-70.

Vandivier, R. W., Fadok, V. A., Hoffmann, P. R., Bratton, D. L, Penvari, C. and Brown, K. K. (2002). Elastase-mediated phosphatidylserine receptor cleavage impairs apoptotic cell clearance in cystic fibrosis and bronchiectasis. Journal of Clinical Investigation 109, 661-70. 